\title{
Chromatic Characteristics Edible Coating of Aloe Gel
}

\author{
L. Suriati ${ }^{1}$, I. M. S. Utama ${ }^{2}$, B. A. Harjosuwono ${ }^{2}$ and I. B. W. Gunam ${ }^{2}$ \\ ${ }^{1}$ Department of Food Science and Technology, Warmadewa University, Denpasar, Indonesia \\ ${ }^{2}$ Department of Agricultural Engineering, Faculty of Agricultural Technology, Udayana University, Denpasar, Indonesia
}

Keywords: Edible Coating, Aloe Gel, Safe Fruit, Fruit Quality.

\begin{abstract}
Edible coating is biodegradable and eco-friendly packaging that current developments. Constituent components of edible coatings in the form of hydrocolloid (polysaccharides, proteins), lipids and composite. The edible coating serves as a protective material which is packed from outside influences also functions as a matrix of antimicrobial agents. Synthetic preservatives that many outstanding raises concerns of the community to use it, because of the high risk on health. One of the potential natural ingredients as an edible coating and also as a natural preservative is aloe vera gel. Edible coating of aloe vera (ECOGEL). Consists of polysaccharide that contains many components of bioactive, but the disadvantage easily becomes diluted. Aloe Vera gel should be kept on the proper environmental conditions. The purpose of this study was to determine the effect of incorporation of various types of additives (citric acid, ascorbic acid, potassium sorbate) on the chromatic characteristics of Aloe gel as an edible coating for 15-day storage. This study used a completely randomized design. The results showed that the best chromatic attributes of Aloe gel were the incorporation with citric acid, ascorbic acid, and potassium sorbate.
\end{abstract}

\section{INTRODUCTION}

The use of edible coating is one of the most popular alternatives to maintain fruits in recent years. Edible coating is a thin layer that is made from materials that can be eaten. This layer serves as a chemical, physical and biological barrier. Edible coating also serves as a carrier of additives, barrier of mass transfer, water vapor, $\mathrm{O} 2$ and $\mathrm{CO}_{2}$ gas exchange (Bourtoom, 2008). The main components of the compiler of edible coatings are hydrocolloid, lipid and composite. Hydrocolloid used in the manufacture of edible coatings in the form of a protein or polysaccharide. One great advantage of using edible coatings are some active ingredient can be incorporated into polymer matrices and consumed with food, so that it can maintain nutrition and sensorial attributes (Dhall, 2008).

Edible coating is an environmentally friendly packaging, easily parsed nature, and shaped thin layer (Dhall, 2008). The phenomenon of edible coating is the formation of structural protection to prevent physical, chemical and biological deterioration of fruit coated. Edible coating serves as an additive carrier and active ingredient, gas displacement barrier, moisture, dissolved and lipid materials
(Bourtoom, 2008). The constituent components of edible coatings are hydrocolloids (proteins, polysaccharides), Lipids and composites (SanchezMachando et al., 2017). The edible coating formulation greatly affects the ability of the adhesion on the surface of the hydrophilic fruit. The advantage of using edible coatings are some additive materials can be incorporation on a polymer matrix (Ahmed et al., 2009).

Synthetic preservatives often raise public concern. One of the natural ingredients that can be used as a preservative and edible coating is aloe gel, because it consists of polysaccharides containing 75 functional components (Rahman et al., 2017). Aloe Gel can form a coating, does not affect the flavour, is safe for the environment, inexpensive and easy to obtain, and easy to apply (Hamman, 2008). But its weakness is the fast changing color, easy dilute, high enzyme activity and oxidation process (Suriati, 2018). The discoloration of the aloe gel affects its effectiveness as an edible coating and is often not acceptable on some products (Hamman, 2008). Therefore, simple processing techniques need to be developed. The incorporation of citric acid additives, ascorbic acid, potassium sorbate, calcium chloride and sorbitol can be done to maintain the stability of 
aloe gel as edible coating (Vargas, 2008; Siddiqui et al., 2011). The study aims to determine the characteristic chromatic edible coating of aloe gel that is incorporated additive material.

\section{MATERIALS AND METHODS}

This study used two-factor complete random draft and three repeats. Factor 1 is the stabilization of the gel with the addition of additive material: citric acid, ascorbic acid, potassium sorbate, calcium chloride, sorbitol. Factor 2 is the storage time treatment of aloe gel in cold temperatures $(7 \pm 1 \mathrm{C}): 0,3,6,9,12$ and 15 days. Variable observations of aloe gel include composition, moisture content, viscosity, $\mathrm{pH}$, color visually, color with the Colorimeter tool. The Data obtained in this study tested statistics with the Analysis of Variance. When the data obtained shows a noticeable effect, then proceed with the Duncan Test.

\section{RESULT AND DISCUSSION}

Aloe Vera Gel is a biopolymer material rich in functional and potential components as an edible coating material. The content of the carbohydrate gel aloe $1.08 \%$, mostly a polysaccharide (Rahman, 2017). Aloe Gel has a $\mathrm{pH}$ of 4.8 which is precisely used as an edible coating of fruits that has a degree of high acidity. The composition of aloe gel before adding additives as shown in table 1.

Table 1: The composition of aloe gel.

\begin{tabular}{lc}
\hline \multicolumn{1}{c}{ Composition } & Amount \\
\hline Water content & $98.46 \%$ \\
Carbohydrate & $1.08 \%$ \\
Protein & $0.036 \%$ \\
Lipid & $0.29 \%$ \\
Ash & $0.21 \%$ \\
pH & 4.8 \\
\hline
\end{tabular}

\subsection{Water Content}

The observation of the water content variable shows that aloe gel contains water of 98.20-99.56\%. The average value of the moisture content of the aloe gel has increased in all the treatment of additive material until Day 9, after which it decreases back. This is because aloe gel is undergoing hydrolysis due to enzyme activity.
The stability of aloe gel is strongly influenced by air, light, heat and enzyme activity (Hamman, 2008). Aloe Gel with the added treatment of citric acid and ascorbic acid has a relatively more stable water content during storage compared to other treatments. The water content of aloe gel with additives during storage can be seen in and Figure 1.

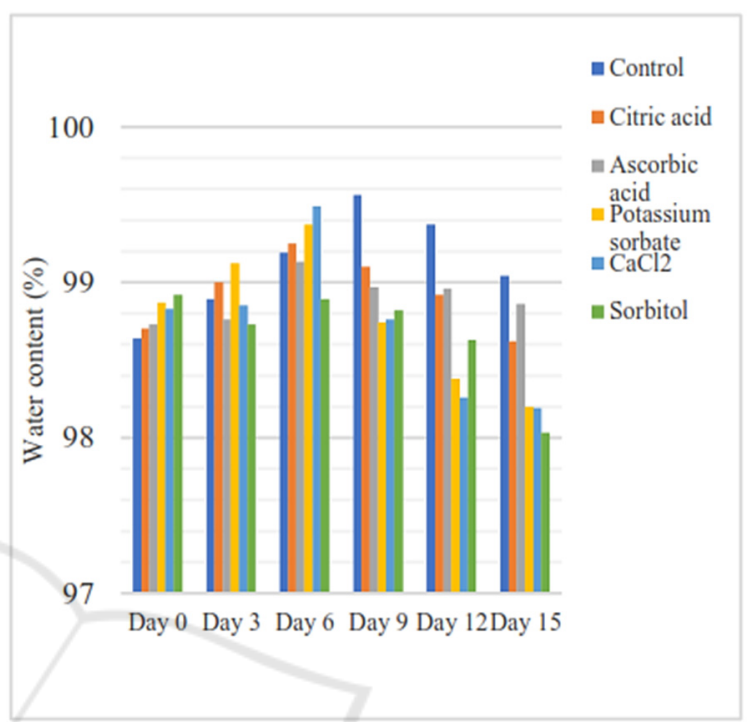

Figure 1: Water content (\%) Aloe gel with additives during storage.

\subsection{Viscosity}

The observation of the viscosity variable indicates that all additive addition treatments result in an increase in the viscosity of aloe gel. Viscosity is influenced by the number and size of particles (Vargas, 2008). The increased viscosity began on the 3 rd day and declined again after the 12th day. This is due to the addition of additives able to strengthen the bond cross linking polymer on aloe gel so that the viscosity is increased.

The viscosity of aloe gel without additives decreases drastically near the viscosity of water at room temperature after 24-36 hours (Ergun and Satici, 2012). The viscosity of aloe gel with additives during storage can be seen Figure 2 . 


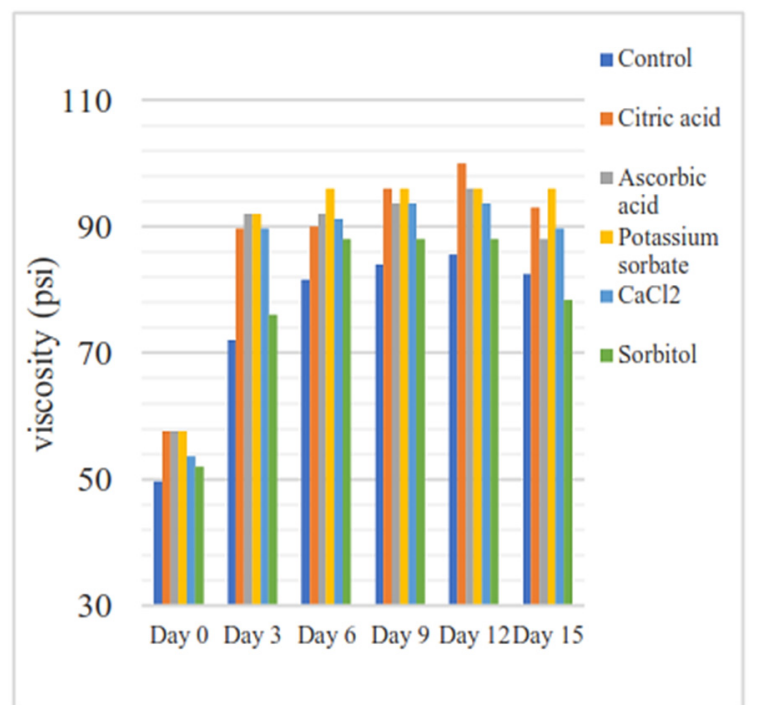

Figure 2: Viscosity (psi) of aloe gel with additive during storage.

\section{$3.3 \mathrm{pH}$}

From the results of various analyses was shown that the $\mathrm{pH}$ of Aloe Vera gel without additives ranged from $\mathrm{pH}$ 4.14-4.62. While the $\mathrm{pH}$ of gels with additive treatment varies from 3.00-4.86. The Gel with citric acid additives and ascorbic is lower compared to sorbate treatment, $\mathrm{CaCl} 2$ and sorbitol. This is due to citric acid and ascorbic acid is an acidulants compound that is able to lower the $\mathrm{pH}$ (Apelblat, 2014). Aloe Gel is stable at low pH.

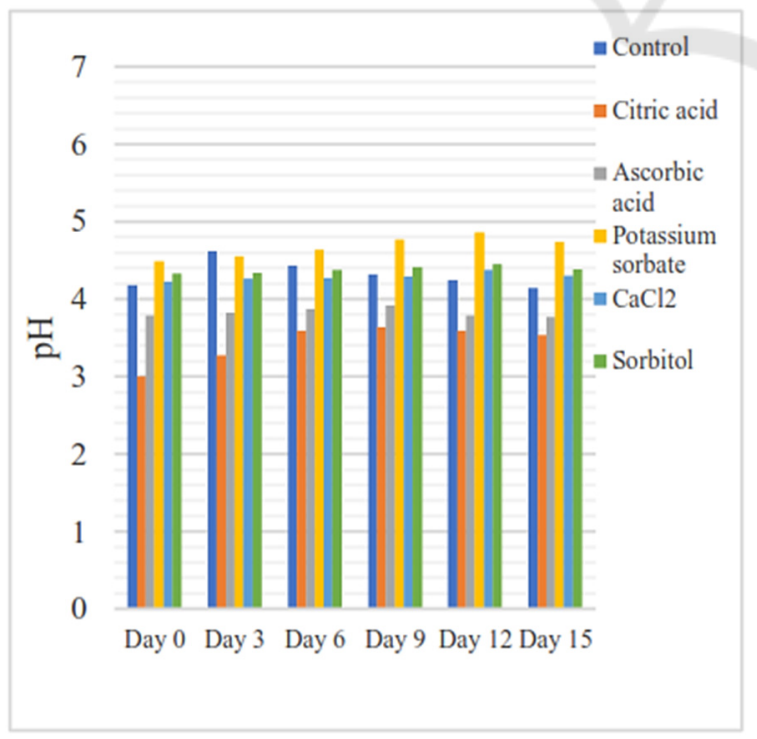

Figure 3: $\mathrm{pH}$ of aloe gel with additives during storage.
The longer the storage of gel $\mathrm{pH}$ with additives tends to stabilize. This is due to the addition of additives capable of activation of enzymes so that the reshuffle of polysaccharide into acids can be prevented (Dhall, 2008). The pH of Aloe Gel with additives during storage can be seen on Figure 3.

\subsection{Color (Visual Observation)}

Based on the results of color observations are visually seen that the aloe gel without heating on the 0 day is transparent white color. On the 3rd day of the ping is coloured and the 12th day is brown. The Gel with a coloured heating treatment ping on day 6 , then yellow Day 12 and Brown Day 15th. The color of the aloe gel relates to its effectiveness and stability as an edible coating. Discoloration of aloe Gel is caused by high enzyme activity (Ramachandra and Rao, 2008). The color of the aloe gel with additives during storage can be seen in Table 2 .

Table 2: Color of aloe gel without additive during storage.

\begin{tabular}{|l|l|l|l|l|}
\hline \multirow{2}{*}{ Day } & \multicolumn{2}{l|}{ Without heating } & \multicolumn{2}{l|}{ heating } \\
\cline { 2 - 5 } & Room & Cool & Room & Cool \\
\hline 0 & White & White & White & White \\
\hline 3 & Ping & Ping & White & White \\
\hline 6 & Brown & Ping & Yellow & Yellow \\
\hline 9 & Brown & Yellow & Yellow & Yellow \\
\hline 12 & Brown & Brown & Brown & Yellow \\
\hline 15 & Brown & Brown & Brown & Brown \\
\hline
\end{tabular}

\subsection{Color (Coordinate $L^{*} A^{*} b^{*}$ )}

Based on the results of color observations with the coordinates $\mathrm{L} * \mathrm{~A} * \mathrm{~b} *$ obtained that aloe gel with additive citric acid and ascorbic acid has the lowest value of $\Delta \mathrm{E}$ or close to control until day 15 while the highest is a gel with $\mathrm{CaCl} 2$. This suggests that citric acid and ascorbic acid are able to suppress changes in the color of the aloe gel so it remains stable and effective as an edible coating. The higher the value of $\Delta \mathrm{E}$ then the aloe gel looks cloudier.

The longer the storage value $\Delta \mathrm{E}$ the higher. This is due to the longer the storage the greater the chances of hydrolysis of the aloe gel polymer. Hydrolysis occurs due to an enzymatic reaction, Causes turbidity components. Besides, there is a browning reaction. The physicochemical properties of aloe gel are also highly influenced by air, light, and heat. If direct contact gel with air and light color to pink until brown, and smell bad (Hamman, 2008; Ahmed et al., 2009). The color of the aloe gel with additives can be seen in Figure 5. 


\section{CONCLUSIONS}

Characteristic chromatic edible coating of aloe gel is influenced by the activity of enzyme, air, light and heat. The color of a good aloe gel is a transparent white that shows its stability and its potency as an edible coating. No additive Aloe Vera Gel on the 3rd day of the color has changed. While the aloe gel with additive citric acid and ascorbic acid is still stable approaching control until day 15 . The most appropriate additive used to produce the best chromatic characteristics of aloe gel as edible coating is citric acid.

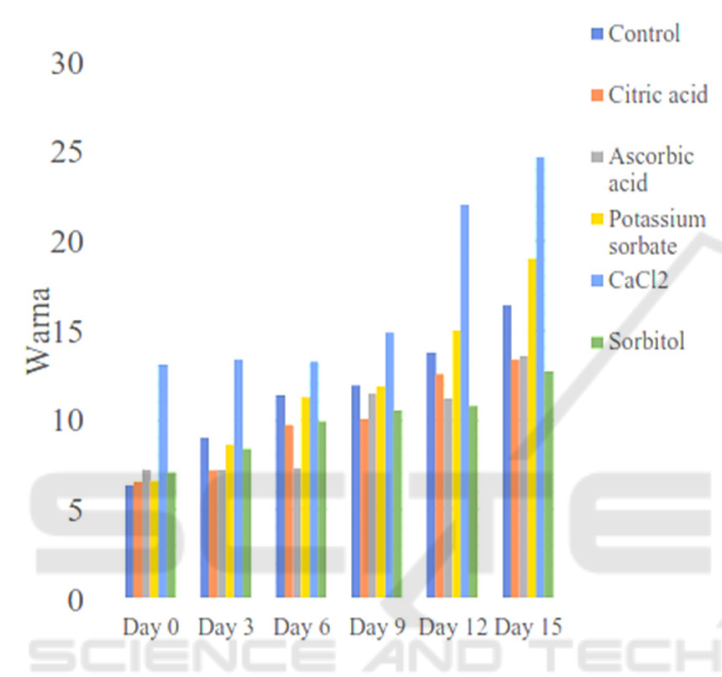

Figure 4: Color aloe gel with additives during storage.

\section{ACKNOWLEDGMENTS}

This research was supported by the competitive grant in the scheme of Strategic Research of National Excellency, Directorate General of Higher Education, Republic of Indonesia. The authors are grateful to the Rector and the Head of Research Institute of Warmadewa University in facilitating to get the grant.

\section{REFERENCES}

Ahmed, M.J, Singh, Z., Khan, A.S., 2009. Postharvest Aloe Vera Gel coating Modulates Fruit Ripening and Quality of 'Arctic Snow' Nectarine Kept in Ambient and Cold Storage, International Journal of Food Science and Technology. 44:1024-1033.
Apelblat, A., 2014. Citric Acid. Springer International Publishing Switzerland. 357.

Bourtoom, T., 2008. Edible Films and Coatings: Characteristics and Properties. International Food Research Journal. 15(3): 237-248.

Dhall, R. K., 2013. Advances in Edible Coatings for Fresh Fruits and Vegetables: a Review. Journal: Critical Review Food Science Nutrition 53(5): 435-450. doi:10.1080/10408398.2010.541568.

Ergun, M., Satici, E. F., 2012. Use of Aloe vera Gel as Bio preservative for 'Granny Smith' and 'Red Chief' Apples M., J. Anim.Plant Sci. 22(2): 363.

Hamman, J. H., 2008. Composition and Applications of Aloe Vera Leaf Gel. Molecules 13(8): 1599-1616. doi:10.3390/molecules13081599.

Rahman, S., Carter, P., Bhattarai, N., 2017. Aloe Vera for Tissue Engineering Applications. Department of Chemical, Biological and Bioengineering, North Carolina A\&T State University, Greensboro, NC 27411, USA.

Ramachandra, C.T., Rao, P.S., 2008. Processing of Aloe vera Leaf Gel: A Review. American Journal of Agricultural and Biological Sciences. 3(2): 502-510.

Sanchez-Machado, D.I., Lopez-Carvantes, J., RaquelSendon, Ana-Sanches-Silva. 2016. Aloe Vera: Ancient Knowledge with New Frontiers. Trends in Food Science \& Technology. DOI: 10.1016/j.tifs.2016.12.005.

Siddiqui W., Chakraborty I., Ayala-Zavala J.F., Dhua R.S., 2011. Advances in Minimal Processing of Fruit and Vagetables: A Review. Journal Scientific \& Industrial Research. 70: 823-834

Suriati, L., Mangku, IG.P., Rudianta, I.N., 2018. The Characteristics of Aloe Vera Gel as An Edible Coating. IOP Conf. Ser.: Earth Environ. Sci. 207012051. doi:10.1088/17551315/207/1/012051.

Vargas, M., Pastor, C., Chiralt, A., McClements, D.J., Inez, C.G., 2008. Recent Advances in Edible Coatings for Fresh and Minimally Processed Fruits. Critical Reviews in Food Science and Nutrition. Taylor and Francis Inc. doi.org/10.1080/ 10408390701537344. 